\title{
Development of a simplified gas ultracleaning process: experiments in biomass residue-based fixed-bed gasification syngas
}

\author{
Christian Frilund $^{1}$ [D $\cdot$ Esa Kurkela ${ }^{1} \cdot$ Ilkka Hiltunen $^{1}$
}

Received: 27 April 2021 / Revised: 18 June 2021 / Accepted: 18 June 2021

(c) The Author(s) 2021, corrected publication 2021

\begin{abstract}
For the realization of small-scale biomass-to-liquid (BTL) processes, low-cost syngas cleaning remains a major obstacle, and for this reason a simplified gas ultracleaning process is being developed. In this study, a low- to medium-temperature final gas cleaning process based on adsorption and organic solvent-free scrubbing methods was coupled to a pilot-scale staged fixed-bed gasification facility including hot filtration and catalytic reforming steps for extended duration gas cleaning tests for the generation of ultraclean syngas. The final gas cleaning process purified syngas from woody and agricultural biomass origin to a degree suitable for catalytic synthesis. The gas contained up to $3000 \mathrm{ppm}$ of ammonia, $1300 \mathrm{ppm}$ of benzene, $200 \mathrm{ppm}$ of hydrogen sulfide, $10 \mathrm{ppm}$ of carbonyl sulfide, and $5 \mathrm{ppm}$ of hydrogen cyanide. Post-run characterization displayed that the accumulation of impurities on the Cu-based deoxygenation catalyst (TOS $105 \mathrm{~h}$ ) did not occur, demonstrating that effective main impurity removal was achieved in the first two steps: acidic water scrubbing (AWC) and adsorption by activated carbons (AR). In the final test campaign, a comprehensive multipoint gas analysis confirmed that ammonia was fully removed by the scrubbing step, and benzene and $\mathrm{H}_{2} \mathrm{~S}$ were fully removed by the subsequent activated carbon beds. The activated carbons achieved $>90 \%$ removal of up to $100 \mathrm{ppm}$ of COS and $5 \mathrm{ppm}$ of HCN in the syngas. These results provide insights into the adsorption affinity of activated carbons in a complex impurity matrix, which would be arduous to replicate in laboratory conditions.
\end{abstract}

Keywords Ultracleaning $\cdot$ Syngas purification $\cdot$ Desulfurization $\cdot \mathrm{HCN} \cdot \mathrm{COS} \cdot$ Gasification $\cdot$ Biomass to liquids

\section{Introduction}

For Europe to decarbonize the transport sector and reach the net-zero GHG emission targets by 2050 that were set by the European Commission requires substantial efforts into a multitude of renewable energy technologies [1, 2]. Producing synthetic transportation fuels from biomass residues presents a feasible pathway for achieving carbon-neutral fuels. Synthetic biofuels can complement the rapid electrification of light-duty vehicles, especially in sectors that are considered difficult to electrify, such as heavy road, aviation, and maritime transportation [3].

VTT develops a staged fixed-bed gasification process intended for operation at a small industrial scale of 10-50 MW in a biomass-to-liquid (BTL) configuration.

Christian Frilund

christian.frilund@vtt.fi

1 VTT Technical Research Centre of Finland Ltd., P.O. Box 1000, FI-02044 Espoo, Finland
Conventionally, fixed-bed biomass gasifiers produce hightar-content gas suitable for power generation, while BTL configurations utilize entrained flow or fluidized-bed gasifiers, which are only appropriate for larger-scale application [4]. The developed gasifier combines an updraft gasifier with a secondary catalytic zone [5]. This approach, in conjunction with a subsequent hot gas cleaning section with filtration and catalytic reforming, ensures sufficient control of solids and volatile organic compounds for the generation of bio-syngas that can be further cleaned in a simplified final gas cleaning step to produce gas suitable for catalytic synthesis purposes. As presented in our previous paper [6], a novel low- to medium-temperature final gas cleaning process based on adsorption and organic solvent-free scrubbing was developed, constructed, and finally coupled to a bubbling-fluidized bed gasifier with hot filter and reformer and downstream Fischer-Tropsch (FT) synthesis. Dry-bed contaminant control is primarily carried out using activated carbons, which are inexpensive multipurpose adsorbents that may also possess beneficial catalytic properties [7]. This 
final gas cleaning process replaces the capital-intensive wetscrubbing processes which are optimized for syngas purification at a larger scale of hundreds of MW of fuel input. Biomass-based syngas purification to a level adequate for synthesis involves the removal of reduced sulfur species, $\mathrm{N}$-group species such as $\mathrm{NH}_{3}$ and $\mathrm{HCN}$, as well as trace benzene and tars, and halogens/metals to sub-ppm concentrations $[8,9]$. This modular unit approach allows different cleaning requirements to be met and gas streams of different impurity concentrations and profiles to be adopted for optimal technical and economical outcomes.

In this study, the final gas cleaning process was coupled to the pilot-scale staged fixed-bed gasifier (SXB) for extendedduration tests to assess and evaluate the performance of gas ultracleaning in real fixed-bed gasification syngas. The final gas cleaning process results for UC5 of the SXB-coupled week-long campaigns are presented in two parts: in the coupled downstream FT synthesis campaigns, SXB20/07 and 11, the aim was to generate downstream utilizable clean syngas, while the final campaign, SXB20/24, was dedicated to gas cleaning development work and analyzing the major impurity concentrations after each final gas cleaning unit operation, with smaller adsorbent quantities to allow for the potential penetration of contaminants. The SXB pilot test results for the gasification facility are available in [5], and more detailed results for the development of the catalytic reformer are presented in [10].

\section{Materials and methods}

\subsection{Experimental setup}

The experiences with final gas cleaning in a fully coupled BTL process train in producing relatively clean BFB gasifier syngas were reported in our previous work [6]. In this study, the final gas cleaning process, UC5, was coupled to the staged fixed-bed gasification facility SXB. The complete gasification and gas cleaning facility is visualized in Fig. 1.

The SXB gasification pilot plant consisted of a biomass feeding system, gasifier, raw gas cooler, filter unit, catalytic reformer, second gas cooler, pressure reducer, and district heating boiler. The gasification pilot plant was operated at target pressures of 200-400 kPa. Hot filtration involved sintered metal filters. The catalytic reformer separately feeds $\mathrm{O}_{2}, \mathrm{~N}_{2}$, and $\mathrm{CO}_{2}$ to the two reformer stages.

Standard conditions are defined as $101,325 \mathrm{kPa}$ and $273.15 \mathrm{~K}$, and in this paper, all flow rates and gas volumes are normalized to standard conditions. Space velocities are volume-based and in real terms. Gas compositions are reported on a dry basis, unless explicitly stated otherwise.

The final gas cleaning process, UC5, was coupled to the SXB gasification facility by a slipstream after the pressure reducer and, thus, the gas feeding was at atmospheric conditions. The decision to operate the first section at atmospheric conditions in the experiments presented in this paper

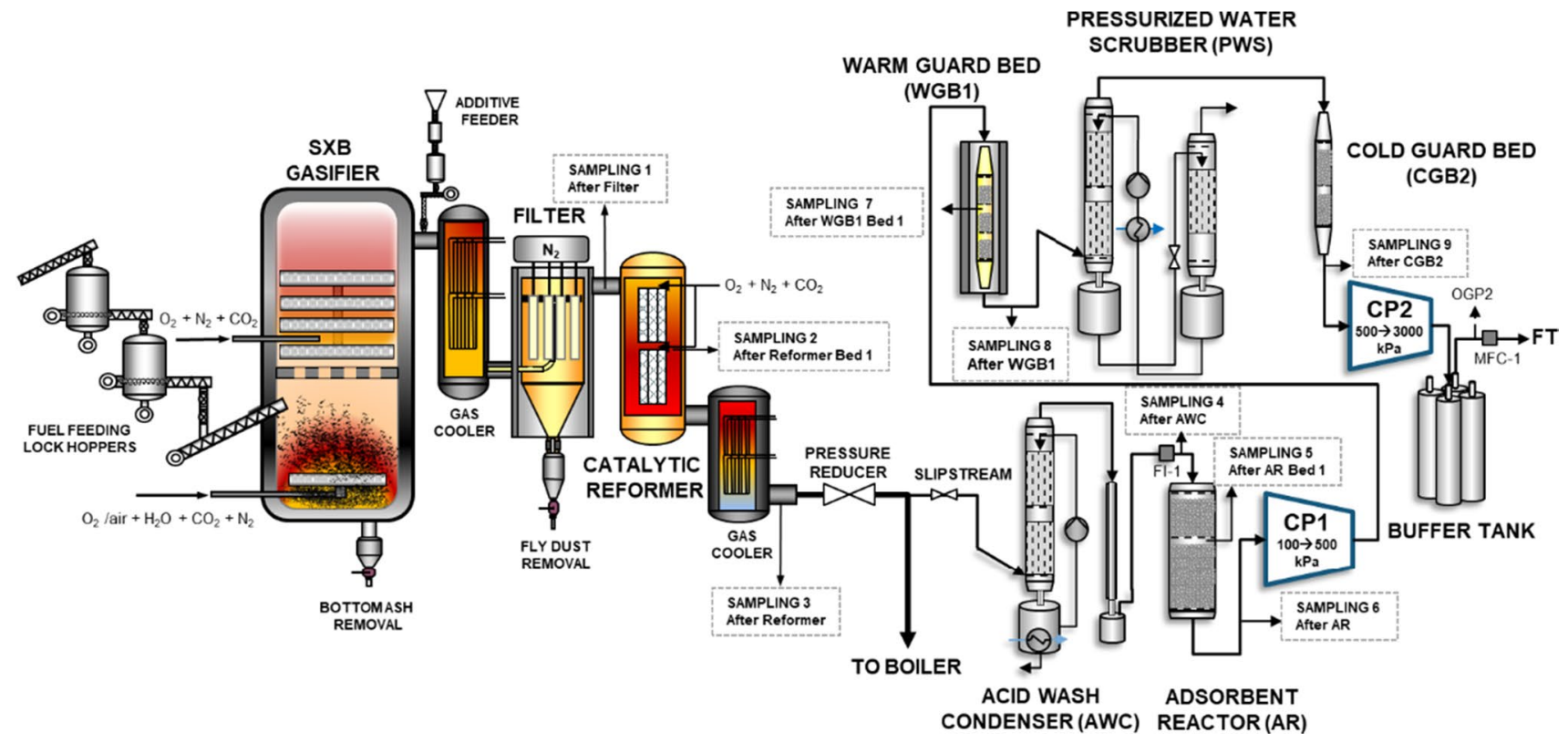

Fig. 1 Schematic of pilot-scale gasification facility SXB, involving staged fixed-bed gasifier, hot filtration, and catalytic reformer. The final gas cleaning process, UC5, was connected to the gasification facility slipstream and included the following units: acid wash column (AWC), adsorbent reactor (AR), compressor 1 (CP1), warm guard bed 1 (WGB1), pressurized water scrubber (PWS), cold guard bed 2 (CGB2), compressor 2 (CP2), buffer tank (BT), and off-gas purge 2 (OGP2) 
was based on previous knowledge of successfully operating the final gas cleaning in this way, but nothing prevents operation of the full process train at pressurized conditions, which improves the efficiency of the system. The acid wash condenser (AWC) consisted of a countercurrent acid wash column (i.d. $0.16 \mathrm{~m}$ ) with formic acid injection into the closed-loop water circulation. The adsorbent reactor (AR) involved two fixed beds (i.d. $0.25 \mathrm{~m}$ ). The AR included air injection and gas moisture (relative humidity $(\mathrm{RH})$ ) adjustment. The two compressors, CP1 and CP2, were of metal diaphragm type by Sera ComPress GmbH. Warm guard bed 1 (WGB1) consisted of a three-stage fixed bed (i.d. $0.08 \mathrm{~m}$ ) placed in a furnace. The pressurized water scrubber (PWS), which consisted of a pressurized countercurrent absorption column (PWS AC) and an atmospheric desorption column (PWS DC) (both i.d. $0.16 \mathrm{~m}$ ), employed $\mathrm{N}_{2}$ as stripping gas. Cold guard bed 2 (CGB2) was a two-stage fixed-bed unit (i.d. $0.08 \mathrm{~m}$ ).

\subsection{Test campaigns and bed materials}

The final gas cleaning process was coupled to the SXB gasification facility in three test campaigns, SXB20/07, SXB20/11, and SXB20/24. These campaigns involved four wood-based and agricultural-derived biomass feedstocks: Finnish wood pellets (WP) and bark pellets (BP), wood chips (WCH) from Lithuania, and sunflower husk pellets (SFP) from Ukraine. Measurements were carried out in up to daylong setpoints (SP) with targeted steady-state operation of the gasification facility. Kurkela et al. [5] previously published results from the same campaigns which also include detailed descriptions of the gasification facility, setpoint conditions, and feedstock characterization; the setpoint naming in this study remains analogous to that paper. Table 1 lists the final gas cleaning runtimes during these campaigns.

Four activated carbon types were used in the process (Jacobi Carbons): two non-impregnated virgin carbons, VAC1 (Ecosorb GXB) and VAC2 (AddSorb Sulfox), and two impregnated carbons, a caustic carbon, $\mathrm{CaAC}$, and an acid impregnated carbon, AcAC.

The principle for packing the materials for the adsorbent reactor (AR) was as follows: VAC1 was packed in bed 1 with

Table 1 Campaign runtimes in coupled mode in terms of SXB-UC5 and SXB-UC5-synthesis time-on-stream (TOS)

\begin{tabular}{llll}
\hline & SXB20/07 & SXB20/11 & SXB20/24 \\
\hline SXB runtime (h) & 62 & 70 & 85 \\
Setpoints and & A, B, C (BP) & A, B, C (WP) & A, B, C, D (WP) \\
feedstock & D (WCH) & D (BP) & E (SFP) \\
& & E (SFP) & F, G (WP) \\
UC5 TOS (h) & 42 & 63 & 75 \\
Synthesis TOS (h) & 38 & 61 & 60 \\
\hline
\end{tabular}

the intention of primarily removing benzene and residual tar. The larger bed 2 was filled with VAC2, intended for $\mathrm{H}_{2} \mathrm{~S}$ removal, as well as a layer of $\mathrm{CaAC}$ at the bottom. CGB2 was packed with impregnated carbons.

A commercial $\mathrm{ZnO}$ adsorbent with alumina, $\mathrm{ZnO1}$ (Actisorb S2, Clariant), was packed in WGB1. A Cu/Zn catalyst, CuZn1 (GetterMax® 133, Research Catalysts Inc.), was employed for deoxygenation of the syngas. In the final campaign, SXB20/24, warm guard bed materials supplied by Johnson Matthey were used: $\mathrm{ZnO} 2$ was zinc oxide adsorbent CP1376, and Al1 was an alumina-based catalyst intended for COS hydrolysis, CP625. Table 2 presents the bed masses and estimated space velocities in each campaign.

The campaigns SXB20/07 and 11 were operated without fresh bed material change in-between the test weeks. For campaign SXB20/24, the bed masses were essentially halved for the AR and the caustic AC bottom layer in bed 2 was removed. For WGB1, ZnO1 was replaced with a combination of alumina catalyst (A11) and zinc oxide ( $\mathrm{ZnO} 2)$, and $\mathrm{CuZn1}$ loading was also significantly decreased.

\subsection{Analytics}

\subsubsection{Gas analytics}

The sampling points after the reformer and after UC5 were connected to a Varian CP-4900 micro GC with thermal conductivity detectors (TCDs), which was used for the analysis of $\mathrm{CO}, \mathrm{CO}_{2}, \mathrm{H}_{2}, \mathrm{CH}_{4}, \mathrm{O}_{2}, \mathrm{~N}_{2}$, and $\mathrm{C}_{2}-\mathrm{C}_{5}$ hydrocarbons. The concentrations of benzene and tars were sampled offline and analyzed following the European tar protocol [11]. Tars were sampled in each test setpoint after hot filtration and after the reformer. In addition, the gas water content was determined from the tar analysis. Ammonia was also analyzed after the reformer by an offline $\mathrm{HCl}$ titration method.

Small species concentrations are presented as parts per million by volume $\left(\mathrm{ppm}=\mathrm{cm}^{3} \mathrm{~m}^{-3}\right)$. Oxygen breakthrough after final gas cleaning was monitored using micro GC and an estimated limit of detection (LoD) of 0.001 volume \% (10 ppm) $\mathrm{O}_{2}$. To detect sulfur compounds, an Agilent 7890A gas chromatograph with a flame photometric detector (FPDGC) and a GS-GASPRO $30 \mathrm{~m} \times 0.32 \mathrm{~mm}$ i.d. column with $\mathrm{He}$ carrier gas was used. The GC was calibrated for $\mathrm{H}_{2} \mathrm{~S}$ and COS using calibration gas at concentrations of 200 and $20.1 \mathrm{ppm}$, respectively, with relative error $\pm 2 \%$. The calibration gas was diluted using $\mathrm{N}_{2}$ to achieve calibration to a minimum of $6 \mathrm{ppm} \mathrm{H}_{2} \mathrm{~S}$ and $0.61 \mathrm{ppm} \mathrm{COS}$. Other sulfur compounds were qualitatively analyzed. The LoD was estimated at $0.1 \mathrm{ppm}$ for $\mathrm{H}_{2} \mathrm{~S}$ and $0.2 \mathrm{ppm}$ for COS.

Fourier transform infrared spectroscopy (FTIR) was carried out using a Gasmet DX4000 to measure $\mathrm{NH}_{3}$, benzene, and $\mathrm{H}_{2} \mathrm{O}$ content in the cleaned syngas. The component reference ranges were as follows: $\mathrm{NH}_{3} 20-120 \mathrm{ppm}$, benzene 
Table 2 UC5 packed materials, masses, and estimated space velocities for campaigns SXB20/07 and 11 and SXB20/24

\begin{tabular}{|c|c|c|c|c|c|}
\hline \multirow[t]{2}{*}{ Unit } & \multirow[t]{2}{*}{ Packing material } & \multicolumn{2}{|c|}{ Packed mass (kg) } & \multicolumn{2}{|l|}{$\mathrm{SV}\left(\mathrm{h}^{-1}\right)^{\mathrm{a}}$} \\
\hline & & SXB20/07\&11 & SXB20/24 & SXB20/07\&11 & SXB20/24 \\
\hline \multicolumn{6}{|c|}{ Adsorbent reactor (AR) } \\
\hline Bed 1 & VAC1 & 2.9 & 1.5 & 900 & 1800 \\
\hline \multirow[t]{2}{*}{ Bed 2} & VAC2 & 8.8 & 4.2 & \multirow{2}{*}{240} & 600 \\
\hline & $\mathrm{CaAC}$ & 1.6 & & & \\
\hline \multicolumn{6}{|c|}{ Warm guard bed 1 (WGB1) } \\
\hline \multirow[t]{2}{*}{ Bed 1} & $\mathrm{ZnO1}$ & 1.3 & & 1500 & \\
\hline & Al1 & & 0.6 & & 5800 \\
\hline \multirow[t]{2}{*}{ Bed 2} & $\mathrm{ZnO1}$ & 1.3 & & 1500 & \\
\hline & $\mathrm{ZnO} 2$ & & 0.5 & & 5800 \\
\hline Bed 3 & $\mathrm{CuZn1}$ & 1.8 & 1.1 & 2300 & 4000 \\
\hline \multicolumn{6}{|c|}{ Cold guard bed 2 (CGB2) } \\
\hline Bed 1 & $\mathrm{AcAC}$ & 1.3 & 1.3 & 1800 & 1800 \\
\hline Bed 2 & $\mathrm{CaAC}$ & 1.3 & 1.1 & 1800 & 2000 \\
\hline
\end{tabular}

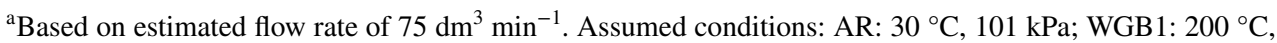
$500 \mathrm{kPa}$; CGB2: $30{ }^{\circ} \mathrm{C}, 450 \mathrm{kPa}$
50-2000 ppm, and $\mathrm{H}_{2} \mathrm{O} 0.1-50 \%$. The limits of detection of the compounds were not separately tested in the syngas matrix.

The gas after AWC was measured in all the campaigns, and an extensive multipoint analysis was performed in campaign SXB20/24 from the following sampling locations: after AWC, after AR bed 1, after AR, after WGB1 bed 1, after WGB1, and after CGB2 (final gas cleaning). Results were calculated from the average of a minimum of three GC samples.

Furthermore, Dräger $\mathrm{H}_{2} \mathrm{~S} 2 / \mathrm{A}$ and $\mathrm{H}_{2} \mathrm{~S}$ 0.2/a (relative error $\pm 5-10 \%$ ), $\mathrm{HCN} 0.5 / \mathrm{a}$ (relative error $10-15 \%$ ), and $\mathrm{HCl}$ 1/a (relative error 10-15\%) colorimetric chemical sensor tubes were used for real-time monitoring of the impurities.

\subsubsection{Bed material characterization}

pH determination A $0.5 \mathrm{~g}$ sample of crushed activated carbon was mixed with $50 \mathrm{~cm}^{3} \mathrm{RO}$ water. The suspension was allowed to stand overnight at room temperature and was then measured using a $\mathrm{pH}$ meter.

SEM/EDS analysis Scanning electron microscopy (SEM) imaging (Carl-Zeiss Merlin) was performed for certain samples. The compositions of the samples were determined by energy dispersive X-ray spectroscopy (EDS). The microscope was equipped with a Thermo Fisher UltraDry energy dispersive X-ray spectrometer (silicon drift detector) with an acceleration voltage of $3 \mathrm{kV}$ for imaging and $10 \mathrm{kV}$ for EDS. Samples were pre-vacuumed and placed in Al stubs for imaging. Some cylindrical samples were broken in the middle to expose the cross-section.
Thermogravimetric analysis Sample heating rate was $10{ }^{\circ} \mathrm{C} \mathrm{min}-1$ at atmospheric pressure in a $1 \mathrm{dm}^{3} \mathrm{~min}^{-1} \mathrm{~N}_{2}$ stream. The sample size was in the $150 \mathrm{mg}$ range. Temperature-programmed heating was performed in the temperature range $25-800{ }^{\circ} \mathrm{C}$, with a holding step at $100{ }^{\circ} \mathrm{C}$.

$\mathrm{N}_{2}$ adsorption/desorption analysis Fresh and spent activated carbons were measured at $-196{ }^{\circ} \mathrm{C}$ using a Micrometrics 3 Flex analyzer with $\mathrm{N}_{2}$ adsorption and desorption isotherms. Samples were pre-dried at $120{ }^{\circ} \mathrm{C}$. For specific surface area determination, the multipoint Brunauer-Emmett-Teller (BET) equation was used. Pore volume was estimated by the Barrett-Joyner-Halenda (BJH) method in a distribution range of micropores of $<2.03 \mathrm{~nm}$ and mesopores of $2.03-40.8 \mathrm{~nm}$.

\section{Results and discussion}

\subsection{Ultraclean gas for downstream application}

Campaign SXB20/07 was the first fully coupled run of the SXB gasification facility with final gas cleaning and synthesis. The SXB20/07 UC5 runtime was shorter than anticipated due to the long pre-heating requirement. To compensate for this, bed material changes were not performed for campaign SXB20/11, and a total runtime of $105 \mathrm{~h}$ with the same bed materials was achieved. The slipstream operation of the downstream processes was successful, and stable pressure levels in the atmospheric side were achieved. Detailed process measurements from select setpoints are presented in the Appendix Table 6. The gas purity was continuously monitored after the final gas cleaning process. The average 
cleaned gas composition is presented in Table 3 for select setpoints, along with the gas composition measured before final gas cleaning.

The major impurities that were monitored included the $\mathrm{N}$-group compounds $\mathrm{NH}_{3}$ and $\mathrm{HCN}$, the S-group compounds $\mathrm{H}_{2} \mathrm{~S}$ and $\mathrm{COS}$, and hydrocarbons including benzene and residual tars. $\mathrm{HCl}$ and $\mathrm{SO}_{2}$ were also analyzed during select setpoints, with none detected. The ammonia concentration in the gas varied significantly, between $350 \mathrm{ppm}$ (wood) and $3300 \mathrm{ppm}$ (sunflower), but this did not affect the removal performance, with ammonia not detected in any of the purified FTIR gas samples. HCN concentration in the gas after the reformer was in the single-digit parts per million range; again, sunflower husk feedstock showed the highest HCN concentration. HCN was also completely removed. Up to $1300 \mathrm{ppm}$ benzene and some tars were detected in the sunflower-based syngas, which is an order of magnitude higher than in the previously reported BFBUC5 campaigns. Benzene or tars were not detected after the UC5 process. The post-reformer syngas sulfur concentration was consistent with the analyzed feedstock sulfur content, with sunflower depicting the highest concentration, up to $220 \mathrm{ppm}_{2} \mathrm{~S}$ and $11 \mathrm{ppm} \mathrm{COS}$. The $\mathrm{H}_{2} \mathrm{~S}$ : COS ratio remained above 10 in the analyzed setpoints. SXB20/07 COS after reformer was not analyzed, but the same feedstock was operated in SXB20/11D with a COS concentration of $6.7 \mathrm{ppm}$. The SXB20/07 setpoints showed a barely detectable breakthrough of COS, estimated at $0.1 \mathrm{ppm}$. This was not detected in the SXB20/11 campaign, which could indicate that the reaction temperature of SXB20/07 in WGB1 was insufficient.

Table 4 presents the post-run characterization results of the non-impregnated activated carbons VAC1 and VAC2 from AR.

The fresh carbons exhibited a basic $\mathrm{pH}$ of above 10, and the $\mathrm{pH}$ of the spent carbons dropped to $8.3-8.8$ as a result of species deposition onto the AC surface. The BET surface area decreased, especially for the bed 1 sample. Micropore volume decreased, but mesopore volume remained unchanged for both spent samples. Sulfur analysis depicted significant increase for VAC1 in bed 1 , while the bed 2 sample had only slightly increased from fresh base levels. Ultimate analysis of elements $\mathrm{C}, \mathrm{H}$, and $\mathrm{N}$ did not display significant deviations from fresh samples.

\subsubsection{Thermogravimetric analysis}

Thermogravimetric analysis was performed in a nitrogen atmosphere for the AR activated carbon samples and reference fresh equivalents. The results are presented in Fig. 2

There were three distinct mass change temperature ranges above baseline, which are grouped according to: $50-105^{\circ} \mathrm{C}$, $105-225^{\circ} \mathrm{C}$, and $200-450{ }^{\circ} \mathrm{C}$. A significant mass change occurred at around $100{ }^{\circ} \mathrm{C}$, which can be attributed to water vaporization. The low temperature range $\left(25-105{ }^{\circ} \mathrm{C}\right)$ accounts for bed 1 around $25 \%$ of the excess mass loss, while for bed 2 it exhibits over $40 \%$. A second high excess mass loss occurred at around a $150-175^{\circ} \mathrm{C}$ peak, and a third
Table 3 Select setpoint average gas compositions before (after reformer, sampling 3) and after (after CGB2, sampling 9) final gas cleaning process, UC5

\begin{tabular}{|c|c|c|c|c|c|c|c|c|c|c|}
\hline \multirow{4}{*}{$\begin{array}{l}\text { Feedstock } \\
\text { TOS (h) }\end{array}$} & \multirow{2}{*}{\multicolumn{2}{|c|}{$\begin{array}{l}\mathrm{SXB} 20 / 07 \mathrm{~A} \\
\mathrm{BP}\end{array}$}} & \multirow{2}{*}{\multicolumn{2}{|c|}{$\frac{\mathrm{SXB} 20 / 07 \mathrm{D}}{\mathrm{WCH}}$}} & \multirow{2}{*}{\multicolumn{2}{|c|}{$\frac{\mathrm{SXB} 20 / 11 \mathrm{~A} 2}{\mathrm{WP}}$}} & \multirow{2}{*}{\multicolumn{2}{|c|}{$\frac{\mathrm{SXB} 20 / 11 \mathrm{D}}{\mathrm{BP}}$}} & \multirow{2}{*}{\multicolumn{2}{|c|}{$\frac{\mathrm{SXB} 20 / 11 \mathrm{E}}{\mathrm{SFP}}$}} \\
\hline & & & & & & & & & & \\
\hline & \multicolumn{2}{|l|}{19.0} & \multicolumn{2}{|l|}{41.5} & \multicolumn{2}{|l|}{63.5} & \multicolumn{2}{|l|}{91.0} & \multicolumn{2}{|l|}{105.0} \\
\hline & Before & After & Before & After & Before & After & Before & After & Before & After \\
\hline $\mathrm{CO}(\%)$ & 13.7 & 16.1 & 13.2 & 15.3 & 14.9 & 16.8 & 15.3 & 17.4 & 12.9 & 14.2 \\
\hline $\mathrm{H}_{2}(\%)$ & 25.2 & 28.5 & 26.9 & 30.4 & 30.7 & 33.5 & 28.3 & 32.4 & 26.2 & 29.4 \\
\hline $\mathrm{CO}_{2}(\%)$ & 28.7 & 17.5 & 27.1 & 16.5 & 28.1 & 16.8 & 31.9 & 19.7 & 32.2 & 19.6 \\
\hline $\mathrm{CH}_{4}(\%)$ & 1.5 & 1.8 & 0.7 & 0.9 & 1.1 & 1.4 & 1.5 & 1.9 & 3.1 & 3.5 \\
\hline $\mathrm{N}_{2}(\%)$ & 30.5 & 36.2 & 32.0 & 36.9 & 25.2 & 31.6 & 23.0 & 28.6 & 25.7 & 33.4 \\
\hline $\mathrm{O}_{2}(\%)$ & 0 & 0 & 0 & 0 & 0 & 0 & 0 & 0 & 0 & 0 \\
\hline $\mathrm{C}_{2}-\mathrm{C}_{5}(\%)$ & 0 & 0 & 0 & 0 & 0 & 0 & 0 & 0 & 0 & 0 \\
\hline $\mathrm{C}_{6} \mathrm{H}_{6}(\mathrm{ppm})^{\mathrm{a}}$ & 520 & 0 & 50 & 0 & 140 & 0 & 400 & 0 & 1300 & 0 \\
\hline $\operatorname{Tars}\left(\mathrm{mg} \mathrm{m}^{-3}\right)^{\mathrm{a}}$ & 30 & 0 & 0 & 0 & 20 & 0 & 27 & 0 & 200 & 0 \\
\hline $\mathrm{NH}_{3}(\mathrm{ppm})$ & 1880 & 0 & 680 & 0 & 350 & 0 & 1600 & 0 & 3270 & 0 \\
\hline $\mathrm{H}_{2} \mathrm{O}(\%)^{\mathrm{a}}$ & 30.2 & 0.4 & 28.1 & 0.4 & 29.3 & 0.5 & 32.0 & 0.5 & 35.9 & 0.5 \\
\hline $\mathrm{H}_{2} \mathrm{~S}(\mathrm{ppm})^{\mathrm{c}}$ & $70^{\mathrm{a}}$ & 0 & $20^{\mathrm{a}}$ & 0 & 22 & 0 & 91 & 0 & $220^{\mathrm{b}}$ & 0 \\
\hline $\operatorname{COS}(\mathrm{ppm})^{\mathrm{c}}$ & $\mathrm{n} . \mathrm{a}$ & 0.1 & n.a & 0.1 & 1.9 & 0 & 7 & 0 & $11^{\mathrm{b}}$ & 0 \\
\hline $\mathrm{HCN}(\mathrm{ppm})^{\mathrm{a}, \mathrm{c}}$ & 2.5 & 0 & 2 & 0 & 0.7 & 0 & 2 & 0 & 6 & 0 \\
\hline
\end{tabular}

${ }^{\mathrm{a}}$ Non-continuous analysis

${ }^{\mathrm{b}}$ Samples taken $0.5 \mathrm{~h}$ before setpoint start

${ }^{\mathrm{c}}$ Samples taken after AWC, sampling 4 
Table 4 Fresh and spent (bed surface sample) AR adsorbent characterization from campaigns SXB20/07 and 11: pH, $\mathrm{N}_{2}$ adsorption/desorption analysis, and sulfur analysis

\begin{tabular}{llllr}
\hline & \multicolumn{2}{l}{ Fresh adsorbent } & \multicolumn{2}{c}{ Spent SXB20/11 } \\
& & & Bed 1 & Bed 2 top \\
\hline & VAC1 & VAC2 & VAC1 & VAC2 \\
\hline $\mathrm{pH}$ & 10.3 & 10.4 & 8.3 & 8.8 \\
$\mathrm{BET}-\mathrm{SA}\left(\mathrm{m}^{2} \mathrm{~g}^{-1}\right)$ & 880 & 1000 & 530 & 900 \\
$\mathrm{~V}_{\text {mic }}\left(\mathrm{cm}^{3} \mathrm{~g}^{-1}\right)$ & 0.33 & 0.35 & 0.21 & 0.31 \\
$\mathrm{~V}_{\text {mes }}\left(\mathrm{cm}^{3} \mathrm{~g}^{-1}\right)$ & 0.06 & 0.11 & 0.06 & 0.12 \\
S-analysis $(\%)$ & 0.34 & 0.35 & 4.4 & 0.74 \\
\hline
\end{tabular}

${ }^{\mathrm{a}}$ Mass fractions

wider range, only occurring for bed 1 , at above $250{ }^{\circ} \mathrm{C}$ and up to $450{ }^{\circ} \mathrm{C}$. The third range accounted for about $60 \%$ of the excess mass loss of the bed 1 sample and can be attributed to elemental sulfur desorption, according to previous studies $[12,13]$. Since the equivalent bed 1 sample S-content was determined to be $4.4 \%$ and the excess mass loss in the range $200-450{ }^{\circ} \mathrm{C}$ ca. $4.1 \%$, the majority of the $105-200{ }^{\circ} \mathrm{C}$ mass loss can be attributed to the desorption of compounds other than sulfur or water, most likely benzene and tars. The bed 2 excess mass loss in the $105-225^{\circ} \mathrm{C}$ range was significantly higher than for bed 1, indicating higher affinity for benzene adsorption. This could also point toward competing adsorption between benzene and sulfur species, with bed 1 first capturing sulfur species to its micropores to the effect of breakthrough of benzene, which is subsequently captured by bed 2 at a higher capacity. Bed 2 was exposed to a lower onstream sulfur concentration, which could explain the higher

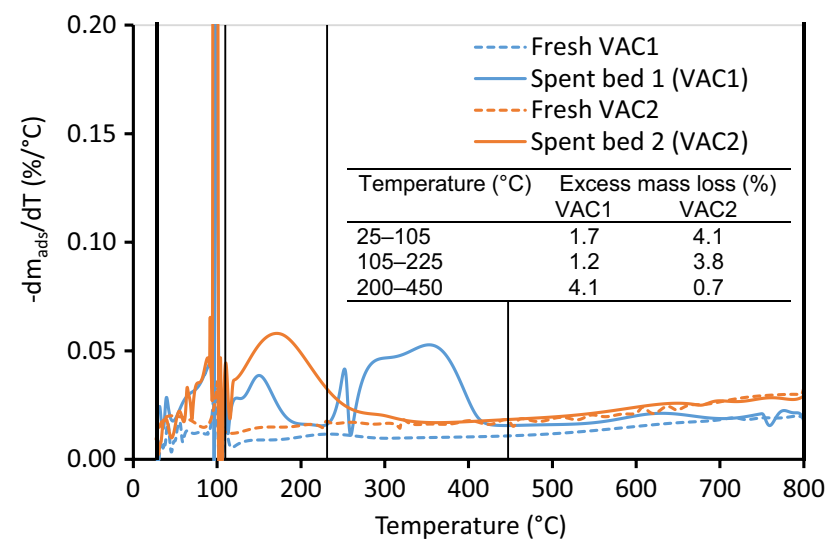

Fig. 2 Thermogravimetric analysis (TGA) in $\mathrm{N}_{2}$ presented as percentage weight change derivative (weight loss) as a function of temperature. Analysis performed for fresh VAC1 (dashed blue line) and VAC2 (dashed orange line). Spent surface samples of SXB20/07 and 11 AR bed 1, VAC1 (blue line), and bed 2, VAC2 (orange line). Excess mass loss is reported according to three temperature ranges which are indicated with solid black lines water content in the pores. Also the larger micropore volume of VAC2 likely improves the overall capture capacity over VAC1.

\subsubsection{SEM and EDS analysis}

The $4 \mathrm{~mm}$ diameter AR activated carbons pellet outer surfaces and cross-sections were imaged using SEM and elemental analysis by EDS. Relative to the reference fresh sample, only the sulfur concentration was higher in the spent samples. In the UC5 process, the AR bed 1 surface was exposed to gas with the highest levels of impurities, and was thus of interest for further characterization. Figure 3 displays the VAC1 sample from AR bed 1 after SXB20/11. For comparison, the figure also shows the spent $\mathrm{CaAC}$ sample from the previous BFB-UC5 campaign II AR bed 1 surface.

The spent VAC1 sample in Fig. 3b shows that the sulfur was fairly evenly deposited in a radial direction due to the high porosity of the non-impregnated activated carbon. By contrast, the caustic carbon from the previous campaign formed a sharp ring pattern with sulfur depositing on the outer surface, up to $1 \mathrm{~mm}$ in depth, due to the presence of caustic impregnate there. The WGB1 zinc oxide and deoxygenation catalyst were imaged and analyzed in a similar manner, shown in Fig. 4.

The $\mathrm{ZnO1}$ zinc oxide adsorbent surface image with EDS sulfur and oxygen overlay (Fig. 4a) depicts two principal macroscale phases, one with significant sulfur content, about 5 atom $\%$, and the other with less than 1 atom $\%$. The sulfurcontaining phase displays also more oxygen, about 50 vs. 40 atom \%, with less zinc than the other phase. The crosssection of spent $\mathrm{ZnO} 1$ sample contained virtually no sulfur; thus, the captured sulfur was limited to the outer surface, depositing in the characteristic uneven pattern depicted in the figure. The surface EDS spectrogram in Fig. $4 \mathrm{~b}$ of the $\mathrm{CuZn1}$ outer surface in Fig. 4c shows no signs of sulfur or other impurities depositing onto the catalyst. Since the reduced copper surface, like other reduced forms of metal catalysts, is exceptionally receptive to impurities like sulfur or halogens, these results confirm that syngas impurities removal occurred in the prior steps. This result also increases the confidence in the gas analysis results shown earlier; there are no signs of undetected or under-detected inorganic impurities. Previous conclusions on the limited need for the final guard bed GCB2 are also confirmed, effectively allowing its elimination and resulting in process simplification.

\subsection{Multipoint gas analysis}

For the final campaign, SXB20/24, the packed bed masses were reduced to achieve more realistic operating conditions in space velocities that could be employed at upscaled operation. 

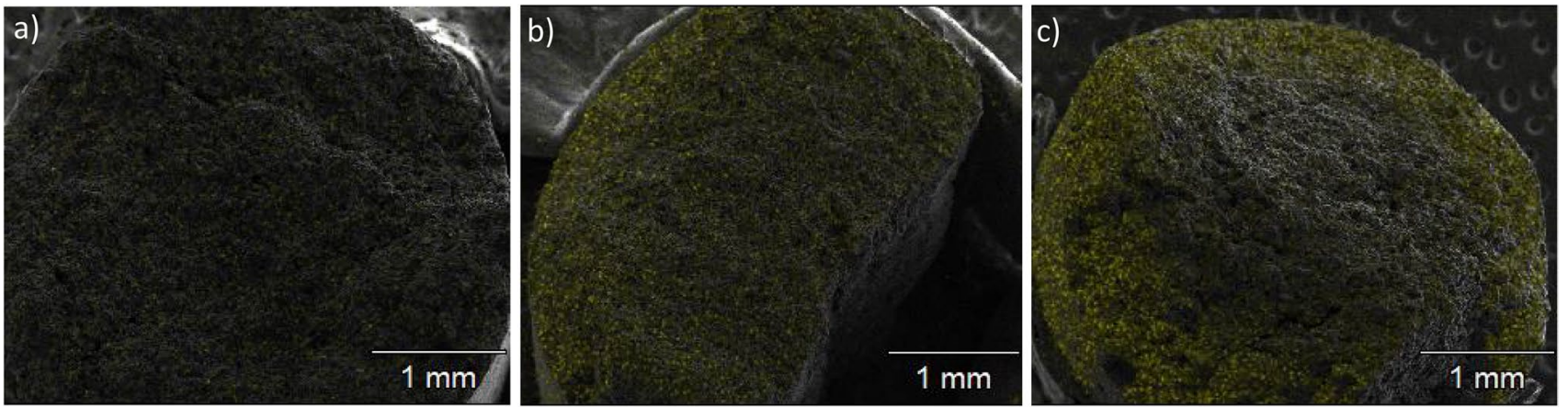

Fig. 3 Activated carbon pellet cross-section images with EDS-analyzed sulfur overlay visualized in yellow: a fresh VAC1; b spent VAC1 from AR bed 1 surface after SXB20/11; $\mathbf{c}$ spent CaAC from AR bed 1 surface after campaign II (TOS $87 \mathrm{~h}$ ), reported in [6]

For multipoint analysis, six sampling points, essentially after each major UC5 unit, were connected to the FPD-GC and FTIR analyzers. Manual switching of sampling points during campaign SXB20/24 setpoints was performed, with at least three samples taken from each sampling point. Sampling order was always in the upstream direction.

Figure 5 presents the multipoint FTIR analysis results from sampling during setpoints B and E2 for ammonia and benzene.

The FTIR analysis of benzene after passing through the acid wash condenser indicates similar concentrations to the offline analysis of sampled ammonia after the reformer due to the low solubility of benzene in water. Benzene in setpoint $B$ was primarily removed by AR bed 1 , but in setpoint E, with $>1000 \mathrm{ppm}$ benzene concentration, a breakthrough occurred. The sample in Fig. 5b was taken at the end of setpoint $\mathrm{E}$, and at this stage, $>750 \mathrm{ppm}$ outlet concentration was measured after AR bed 1. The bulk of the benzene was thus removed by AR bed 2. A possible benzene desorption effect in the subsequent setpoints was observed, with higher concentrations measured after bed 1 than the feed benzene concentration. Once the bed was saturated, the weakly bound benzene, according to the analysis results, was seemingly partly released to the gas stream. The pore volume changes in SXB20/07 and 11 for the spent bed 1 and 2 carbons indicate that the benzene was adsorbed to the micropores. Analogous to the findings of Oliver et al. [14], it shows that benzene vapor adsorption occurred through physisorption and that breakthrough time was dependent on the adsorbent surface area and micropore volume. The equilibrium capacity of benzene and other hydrocarbon impurities, such as toluene, on microporous activated carbons is decent, which increases with higher impurity partial pressure. With commercially available carbons, equilibrium capacities up to between 200 and $350 \mathrm{mg} \mathrm{g}^{-1}$ have been measured $[15,16]$. With a bed height of only $2.5 \mathrm{~cm}$, a fast breakthrough is expected as fixed-bed operated benzene capture by physisorption is improved with increased contact time with the adsorbent. The small bed height is also suspected to lead to premature breakthrough due to the mass transfer zone (MTZ) exceeding the bed height [17]. From a process design perspective, the possibility of frequent bed
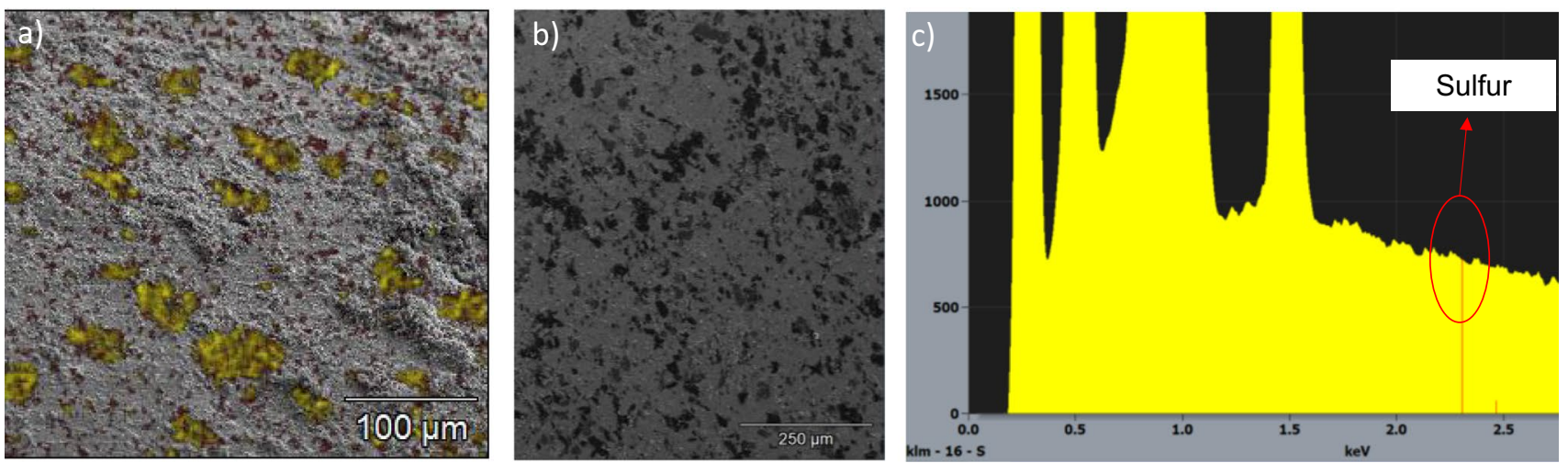

Fig. 4 Spent bed materials from WGB1 after campaign SXB20/11: a surface image of $\mathrm{ZnO} 1$ from bed 1 surface with EDS-analyzed sulfur overlay visualized in yellow and excess oxygen in dark red; $\mathbf{b}$ surface image of spent CuZn1 from AR bed 3 surface; $\mathbf{c}$ surface EDS analysis spectrogram of CuZn1 from AR bed 3 surface 
changes and rapid regeneration of the spent adsorbent would be required if high benzene removal efficiency is required. Fortunately, the purity requirement of benzene for catalytic synthesis applications is not expected to be as strict as with many other impurities.

Observation that a higher gas humidity negatively affects benzene removal has been reported [18]. This is in contrast to $\mathrm{H}_{2} \mathrm{~S}$ removal by activated carbons, which benefits from moisture in gas [12]. Activated carbons are inherently hydrophobic, but if the pore size of the activated carbon is sufficiently small, then the adsorption energy increases, and water can be adsorbed. Water adsorbs to the narrow micropores and especially to hydrophilic sites, which blocks benzene physisorption [18, 19]. By tailoring activated carbons for low moisture affinity, benzene removal can be improved. On the other hand, fine-tuning of the porous texture negatively affects the regeneration potential
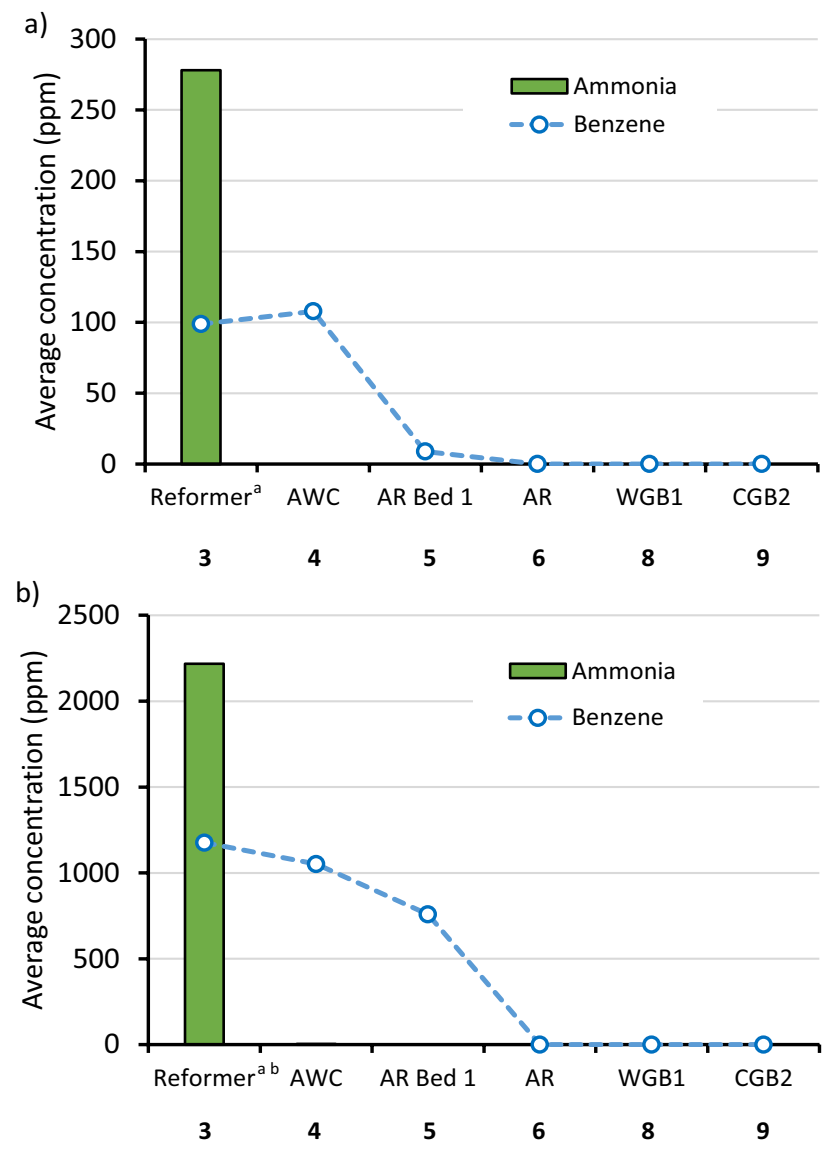

Fig. 5 Campaign SXB20/24 multipoint FTIR analysis for $\mathrm{NH}_{3}$ and benzene during: a setpoint B with wood pellet (WP) feedstock and $\mathbf{b}$ setpoint E2 with sunflower husk pellet (SFP) feedstock. The sampling point number and unit after which sampling was performed are indi-

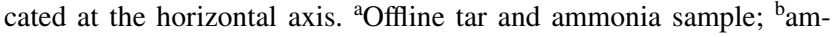
monia sample from setpoint E1 of adsorbents, with the best regeneration results achieved with adsorbents that show a wider pore size distribution. Several methods for regeneration are available, including the most common, thermal regeneration, but pressure methods, solvent extraction, and other methods, such as microwave regeneration, exist [20-22]. Thermal regeneration involves an inert gas, steam, or air, with the previous results in [23] indicating high VOC capturing capacity after several regeneration cycles.

The 300 ppm ammonia in setpoint B was fully removed in the AWC, in which the circulating water $\mathrm{pH}$ was fixed at 3. Setpoint E2 contained $2200 \mathrm{ppm} \mathrm{NH}_{3}$, and this was also removed by acid washing. With these results, it appears that for similar ammonia removal performance, even a higher $\mathrm{pH}$ could suffice. This would decrease acid consumption which, here, was in the formic acid: $\mathrm{NH}_{3}$ mol ratio range of 5-6, relatively independent of ammonia concentrations. Increasing the $\mathrm{pH}$ would, however, increase the absorption of acidic gasses, which would potentially increase the costs of wastewater treatment. The treatment costs can be further decreased by minimizing the amount of wastewater by performing hot syngas water condensation at least partially separated from the acid injection water scrubbing. Choosing a strong acid, such as sulfuric acid, minimizes acid consumption by ensuring full dissociation in water. The product of ammonia removal by aqueous sulfuric acid is ammonium sulfate, which can be precipitated and used as a fertilizer [24].

For detected sulfur compounds, $\mathrm{H}_{2} \mathrm{~S}$ and COS, the multipoint analysis is depicted in the bar charts in Fig. 6 for different sulfur concentration setpoints B (wood) and E2 (sunflower husk). Sulfur compound concentrations after AWC was considered to equal post-reformer concentration due to their low affinity for absorption in acidic water.

As presented in Fig. 6a, the $\mathrm{H}_{2} \mathrm{~S}$ :COS ratio in the low-sulfur wood pellet syngas shifted to a significantly lower value in the post-reformer syngas. This is evidently due to changes in the catalyst loading of the second reformer bed, since the ratio far exceeds the predicted thermodynamic equilibrium. Before SXB20/24, the previously used combination of nickel and bimetallic precious metal catalyst was replaced by a thin layer of nickel followed by a larger layer of platinum-based methane-reforming catalysts. The COS concentration in setpoint $B$ reached up to $6 \mathrm{ppm}$, with the majority removed in AR beds 1 and 2. These results establish in addition to the SXB20/07 and 11 post-run bed material characterization results that $\mathrm{AC} 1$ in bed 1 removed sulfur compounds, while the primary intention was to remove benzene and residual tars. To promote more selective and effective removal of each species, i.e., with bed 1 for removal of hydrocarbons and bed 2 for removal of sulfur compounds, air/oxygen feeding to the adsorbent reactor should be directed to bed 2 . In 
our previous articles, it was established that $\mathrm{H}_{2} \mathrm{~S}$ removal by the oxidative route in moist gas is limited to low space velocities in its application, while the removal rate significantly improves by the presence of ammonia in syngas [25, 26]. Although a high $\mathrm{H}_{2} \mathrm{~S}$ removal rate was achieved even in the small bed 1 , ammonia-enhanced desulfurization unlikely occurred. For $\mathrm{H}_{2} \mathrm{~S}$ removal purposes, the bed size can be further decreased if partial ammonia breakthrough is allowed at the AWC. The most effective way to achieve this is to bypass a small slipstream of the raw syngas past the AWC.

The Al1 aluminum catalyst in WGB 1 bed 1 did not achieve particularly high COS conversion. COS was not detected after the full final gas cleaning process and, thus, the remaining trace amount $\operatorname{COS}(<0.5 \mathrm{ppm})$ was likely adsorbed by the carbons in CGB2. Setpoint E, with sunflower husk feedstock, displayed remarkably high COS concentrations, especially in E2, estimated at around $100 \mathrm{ppm}$. COS is less acidic and less polar than $\mathrm{H}_{2} \mathrm{~S}$, and therefore
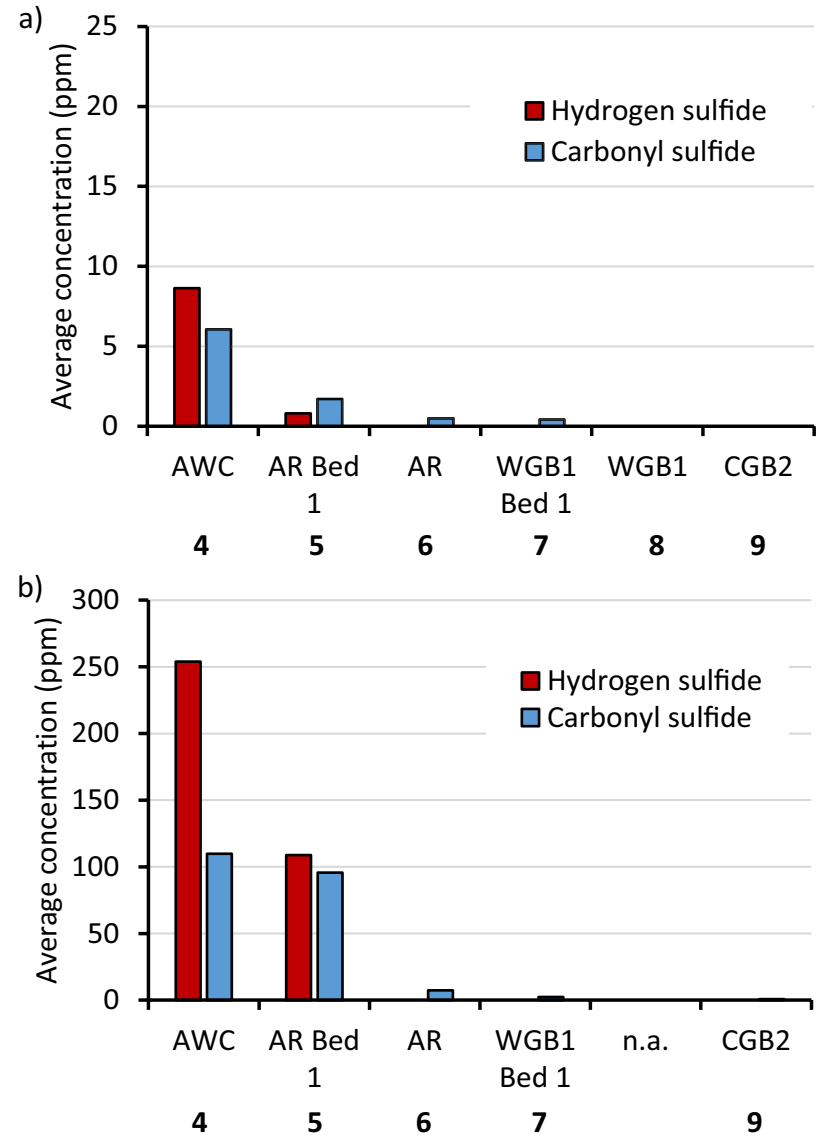

Fig. 6 Multipoint FPD-GC gas analysis for $\mathrm{H}_{2} \mathrm{~S}$ and $\mathrm{COS}$ in campaign SXB20/24 during: a setpoint $B$ with wood pellet (WP) feedstock and b setpoint E2 with sunflower husk pellet (SFP) feedstock. The sampling point number and unit after which sampling was performed are indicated at the horizontal axis harder to remove with adsorbents [27, 28]. Surprisingly, COS was removed by AR bed 2 to levels around $7 \mathrm{ppm}$ throughout the 15-h long setpoint E. Subsequently, an average of $70 \%$ removal of the remaining COS in WGB1 bed 1 was achieved, though no formation of $\mathrm{H}_{2} \mathrm{~S}$ was detected. In setpoint E2, a 0.7 ppm COS breakthrough after the full process was detected. There are very few investigations of carbonyl sulfide adsorption on activated carbons since more abundant sulfur species, such as $\mathrm{H}_{2} \mathrm{~S}$ and $\mathrm{SO}_{2}$, have been of primary interest. Fixed-bed breakthrough tests by Sattler et al. [29] illustrated that the COS adsorption rate is slow with a low uptake capacity, at $<5 \mathrm{mg} \mathrm{g}^{-1}$. In a gas mixture also containing $\mathrm{H}_{2} \mathrm{~S}$, the COS partially competed with $\mathrm{H}_{2} \mathrm{~S}$ in adsorption, leading to significantly lower capacities $\left(0.5 \mathrm{mg} \mathrm{g}^{-1}\right.$ for COS, $4 \mathrm{mg} \mathrm{g}^{-1}$ for $\left.\mathrm{H}_{2} \mathrm{~S}\right)$. In addition, higher humidity negatively affected COS capture capacity, and ammonia did not affect performance. Reports by Qiu et al. [30] and Wang et al. [27] on modified activated carbons depicted higher capture capacity using, for example, metal or $\mathrm{KOH}$ impregnate. COS uptake was improved by higher $\mathrm{O}_{2}$ concentration and, thus, an oxidative reaction mechanism was proposed [27]. Since the high COS concentration setpoint was operated in this study for only a short period, the feasibility of COS removal by adsorption cannot be determined. Nevertheless, COS adsorption remains an interesting topic for future work.

Finally, multipoint analysis was performed for setpoint $\mathrm{G}$ with the wood pellet gasification feedstock for HCN. Figure 7 displays the results.

The wood-based syngas contained a relatively small amount of HCN, about $1.4 \mathrm{ppm}$, as measured after the reformer sampling point with a condensing step. It was established that the acid-washing step did not effectively remove $\mathrm{HCN}$. $\mathrm{HCN}$ is weakly acidic and, therefore, its absorption is low in water at $\mathrm{pH} 3$. The first activated carbon bed in AR was not effective in HCN removal either, likely due to bed saturation; however, $\mathrm{HCN}$ was removed in bed 2 to concentrations below $0.05 \mathrm{ppm}$. Again, no $\mathrm{HCN}$ was detected after UC5. HCN adsorption on non-impregnated carbon occurs by weak physisorption. Methods to improve sorption include impregnation with $\mathrm{Cu}$ or $\mathrm{Cr}$, which form stable complexes with cyanide [31, 32]. Seredych et al. [33] established that the surface chemistry of non-impregnated activated carbon greatly affects adsorption performance, and with basic surface $\mathrm{pH}$ induced by, for example, nitrogen groups, the surface reactions that result in the formation of stable compounds being deposited in micropores can be promoted.

Table 5 summarizes the impurity concentrations and their removal locations in the high impurity sunflower husk feedstock setpoint E2. 
The gas purity goals listed in the table were used in the campaigns to decouple the downstream synthesis unit in case the breakthrough limit was achieved. Impurity concentrations from the literature were adapted for the detection limits of the analyzers employed in this paper. As there was COS breakthrough in high-impurity setpoint E, synthesis was decoupled during this period. Nevertheless, it stands noteworthy that such deep impurity cleaning was achieved with the smaller packed bed loadings in the dirty syngas.

The results, displaying the removal locations for impurities from campaign SXB20/24, provide valuable insights into the adsorption affinity of activated carbons in a complex impurity matrix, which would be difficult to replicate in laboratory conditions. These will be of benefit to continued development of the ultracleaning process and scale-up efforts. In the FlexCHX project, a preliminary 50-MW plant design was completed including an ultracleaning process based on a fully pressurized UC5 concept and single-stage compression to synthesis pressure.

The results of the campaigns presented in this study indicate that for activated carbons, competitive adsorption to microporous sites occurs not only between the removed impurities but also for the water vapor. Promoting more selective removal of impurities could improve the overall removal efficiency. For this, the selection of specific activated carbon types for each impurity removal step could be effective; on the other hand, optimizing the conditions, e.g., bed-specific moisture content and chemical injection adjustment, may suffice.

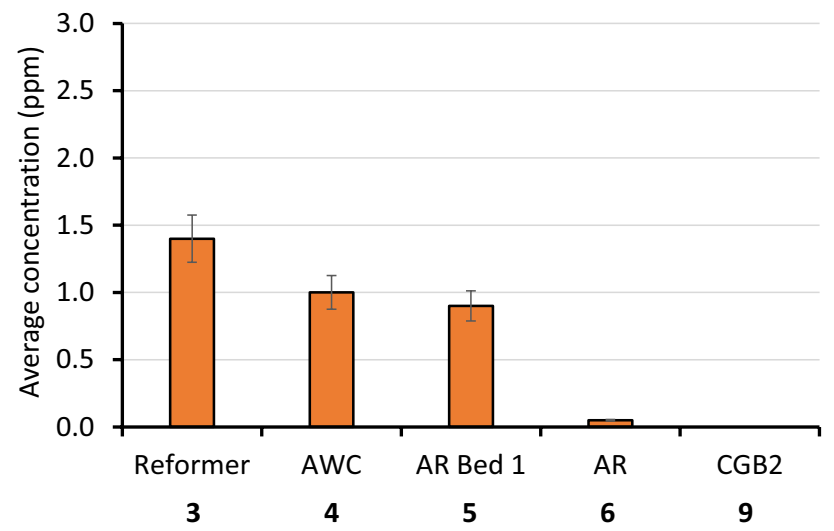

Fig. 7 Campaign SXB20/24 multipoint analysis for HCN during setpoint $\mathrm{G}$ with wood pellet (WP) feedstock. The sampling point number and unit after which sampling was performed are indicated at the horizontal axis
Table 5 UC5 average syngas impurity concentrations in campaign SXB20/24 setpoint E2 with removal location and primary removal unit removal rate $(\mathrm{RR})$

\begin{tabular}{llllll}
\hline Species & Before & Limit & After & Primary removal & $\begin{array}{l}\text { Primary } \\
\text { RR }(\%)\end{array}$ \\
\hline $\mathrm{H}_{2} \mathrm{~S}(\mathrm{ppm})$ & 250 & & 0 & AR bed 2 & 100 \\
$\mathrm{COS}(\mathrm{ppm})$ & 110 & 0.1 & 0.7 & AR bed 2 & 93 \\
$\mathrm{NH}_{3}(\mathrm{ppm})$ & 2200 & & 0 & AWC & 100 \\
$\mathrm{HCN}(\mathrm{ppm})$ & n.a & 0.1 & 0 & AR bed 2 & $97^{\mathrm{a}}$ \\
$\mathrm{HCl}(\mathrm{ppm})$ & n.a & 0.1 & 0 & - & - \\
$\mathrm{O}_{2}(\%)$ & $0.06^{\mathrm{b}}$ & 0.01 & 0 & WGB1 bed 3 & 100 \\
$\mathrm{C}_{6} \mathrm{H}_{6}(\mathrm{ppm})$ & 1150 & 10 & 0 & AR & 100 \\
$\mathrm{CO}_{2}(\%)$ & 27 & - & 17 & PWS & 42 \\
\hline
\end{tabular}

${ }^{\mathrm{a}}$ Based on setpoint $\mathrm{B}$ results

${ }^{\mathrm{b}}$ Calculated concentration from $0.2 \mathrm{dm}^{3} \mathrm{~min}^{-1}$ air injection before $\mathrm{AR}$ and $75 \mathrm{dm}^{3} \mathrm{~min}^{-1}$ syngas flowrate

\section{Conclusions}

The UC5 adsorbent- and solvent-free scrubbing-based final gas cleaning process was successfully operated coupled to the staged fixed-bed SXB gasification facility to produce ultraclean gas for application in Fischer-Tropsch synthesis. The final gas cleaning process purified the syngas after hot filtration and catalytic reforming that contained up to 3000 ppm ammonia, 1300 ppm benzene, 200 ppm hydrogen sulfide, $10 \mathrm{ppm}$ carbonyl sulfide, and $5 \mathrm{ppm}$ hydrogen cyanide. The week-long campaigns established the feasibility of fixed-bed gasification generated clean syngas using similar hot gas cleaning and final gas cleaning systems as previously developed for fluidized-bed gasifiers. Post-run bed material characterization results indicate that no accumulation of impurities on the $\mathrm{Cu}$-based deoxygenation catalyst (TOS $105 \mathrm{~h}$ ) had occurred, signifying that effective removal of all impurities occurred in the first three steps: acid washing, activated carbon beds, and zinc oxide beds.

The final campaign multipoint gas analysis confirmed that ammonia was fully removed by the AWC, and benzene was removed by both activated carbon beds in AR, with the saturation of bed 1 at the end of the campaign. $\mathrm{H}_{2} \mathrm{~S}$ was partly removed by AR bed 1 and fully removed by bed 2 . The COS at high concentrations up to $100 \mathrm{ppm}$ in the SXB20/24 campaign was fully removed in AR, suggesting an affinity of activated carbons for COS removal even in a competing adsorption environment. HCN was also mostly removed by activated carbons. These real-syngas derived findings could provide opportunities for more specific impurities removal research. 


\section{Appendix}

Table 6 Select setpoint average UC5 process measurements

\begin{tabular}{|c|c|c|c|c|}
\hline & & SXB20/07A & SXB20/11A2 & $\mathrm{SXB} 20 / 24 \mathrm{E}$ \\
\hline \multicolumn{2}{|l|}{ Feedstock } & $\mathrm{BP}$ & WP & SFP \\
\hline \multicolumn{2}{|c|}{ Flowrate $\left(\mathrm{dm}^{3} \mathrm{~min}^{-1}\right)$} & 75 & 75 & 75 \\
\hline \multicolumn{5}{|c|}{ Pressure $(\mathrm{kPa})$} \\
\hline \multicolumn{2}{|c|}{ Before CP1 } & 101 & 102 & 104 \\
\hline \multicolumn{2}{|c|}{ Before CP2 } & 450 & 410 & 450 \\
\hline \multicolumn{5}{|c|}{ Temperature $\left({ }^{\circ} \mathrm{C}\right)$} \\
\hline \multirow[t]{2}{*}{ AWC } & Gas before & 147 & 137 & 135 \\
\hline & Gas after & 26 & 29 & 29 \\
\hline $\mathrm{AR}$ & Bed 2 & 29 & 26 & 26 \\
\hline \multirow[t]{3}{*}{ WGB1 } & Bed 1 & 206 & 208 & 210 \\
\hline & Bed 2 & 216 & 218 & - \\
\hline & Bed 3 & 225 & 225 & 225 \\
\hline PWS & Water & 15 & 16 & 19 \\
\hline CGB2 & Bed $1+2$ & 23 & 23 & 26 \\
\hline \multicolumn{5}{|c|}{ Other parameters/measurements } \\
\hline AWC & Water $\mathrm{pH}$ & 3.0 & 3.0 & 3.0 \\
\hline AWC & Acid: $\mathrm{NH}_{3}$ mol ratio & 5.3 & 5.4 & 6.3 \\
\hline AR & $\mathrm{O}_{2}: \mathrm{H}_{2} \mathrm{~S}$ mol ratio & 7 & 24 & 2.1 \\
\hline AR & $\mathrm{RH}(\%)$ & 60 & 62 & 62 \\
\hline PWS AC & $\mathrm{H}_{2} \mathrm{O}$ flowrate $\left(\mathrm{dm}^{3} \mathrm{~min}^{-1}\right)$ & 17.5 & 17.5 & 17.5 \\
\hline
\end{tabular}

Abbreviations AC: Activated carbon; AR: Adsorbent reactor; AWC : Acid wash condenser; BET: Brunauer-Emmett-Teller; BJH: BarrettJoyner-Halenda; BP: Bark pellet; BTL: Biomass to liquids; CGB: Cold guard bed; CP: Compressor; EDS: Energy dispersive X-ray spectroscopy; FPD: Flame photometric detector; IAC: Impregnated activated carbon; MTZ: Mass transfer zone; n.a.: Not analyzed; PWS: Pressurized water scrubber; RH: Relative humidity; RO: Reverse osmosis; SA: Surface area; SEM: Scanning electron microscopy; SFP: Sunflower husk pellet; SV: Space velocity (volumetric); TGA: Thermogravimetric analysis; TOS: Time on stream; WCH: Wood chips; WGB: Warm guard bed; VOC: Volatile organic compound; WP: Wood pellet

Acknowledgements The authors would like to thank the laboratory staff for their contributions: Petri Hietula, Patrik Eskelinen, and Mirja Muhola.

Funding Open access funding provided by Technical Research Centre of Finland (VTT). This work was carried out as part of the FlexCHX project, which received funding from the European Union's Horizon 2020 Research and Innovation Programme under grant number 763919. This research was also supported by the European Union Horizon 2020 project COMSYN, grant number 727476 .

\section{Declarations}

Conflict of interest The authors declare no competing interests.
Open Access This article is licensed under a Creative Commons Attribution 4.0 International License, which permits use, sharing, adaptation, distribution and reproduction in any medium or format, as long as you give appropriate credit to the original author(s) and the source, provide a link to the Creative Commons licence, and indicate if changes were made. The images or other third party material in this article are included in the article's Creative Commons licence, unless indicated otherwise in a credit line to the material. If material is not included in the article's Creative Commons licence and your intended use is not permitted by statutory regulation or exceeds the permitted use, you will need to obtain permission directly from the copyright holder. To view a copy of this licence, visit http://creativecommons.org/licenses/by/4.0/.

\section{References}

1. European Environment Agency (2020) Trends and projections in Europe 2020 - tracking progress towards Europes climate and energy targets. In: EEA rep. no 15/2019. https://www.eea.europa. $\mathrm{eu} /$ publications/trends-and-projections-in-europe-1. Accessed 15 March 2021

2. European Union (2020) Towards a climate-neutral europe: curbing the trend. https://ec.europa.eu/clima/sites/default/files/toward climate_neutral_europe_en.pdf. Accessed 15 March 2021

3. Hannula I, Reiner DM (2019) Near-term potential of biofuels, electrofuels, and battery electric vehicles in decarbonizing road transport. Joule 3:2390-2402. https://doi.org/10.1016/j.joule. 2019.08.013 
4. Hofbauer H (2012) Large scale biomass gasification for electricity and fuels. In: Meyers RA (ed) Encyclopedia of sustainability science and technology. Springer, New York, pp 753-775

5. Kurkela E, Kurkela M, Hiltunen I (2021) Pilot-scale development of pressurized fixed-bed gasification for synthesis gas production from biomass residues. Biomass Convers Biorefinery. https://doi. org/10.1007/s 13399-021-01554-2

6. Frilund C, Tuomi S, Kurkela E, Simell P (2021) Small- to medium-scale deep syngas purification: biomass-to-liquids multicontaminant removal demonstration. Biomass Bioenergy 148:10. https://doi.org/10.1016/j.biombioe.2021.106031

7. Hanaoka T, Matsunaga K, Miyazawa T et al (2012) Hot and dry cleaning of biomass-gasified gas using activated carbons with simultaneous removal of tar, particles, and sulfur compounds. Catalysts 2:281-298. https://doi.org/10.3390/catal2020281

8. Boerrigter H, Uil H Den, Calis H-P (2002) Green diesel from biomass via Fischer-Tropsch synthesis: new insights in gas cleaning and process design. Pyrolysis gasif biomass waste, expert meet. Paper presented at: Pyrolysis and Gasification of Biomass and Waste, Expert Meeting, 30 September - 1 October 2002, Strasbourg, France, pp 1-13. http://citeseerx.ist.psu.edu/viewdoc/ download?doi=10.1.1.466.4185\&rep=rep1\&type $=$ pdf

9. Leibold H, Hornung A, Seifert H (2008) HTHP syngas cleaning concept of two stage biomass gasification for FT synthesis. Powder Technol 180:265-270. https://doi.org/10.1016/j.powtec.2007. 05.012

10. Kurkela E, Frilund C, Kurkela M et al (2021) Flexible hybrid process for combined production of heat, power and renewable feedstock for refineries. Johnson Matthey Technol Rev 44:539-543. https://doi.org/10.1595/205651321x16013744201583

11. European Tar Protocol TC BT/TF 143 (2004) Biomass gasification - tar and particles in product gases - sampling and analysis. http:// www.tarweb.net/results/pdf/CEN-Tar-Standard-draft-version-2 1-new-template-version-05-11-04.pdf. Accessed 19 March 2021

12. Bandosz TJ (2002) On the adsorption/oxidation of hydrogen sulfide on activated carbons at ambient temperatures. J Colloid Interface Sci 246:1-20. https://doi.org/10.1006/jcis.2001.7952

13. Nguyen-Thanh D, Bandosz TJ (2005) Activated carbons with metal containing bentonite binders as adsorbents of hydrogen sulfide. Carbon N Y 43:359-367. https://doi.org/10.1016/j.carbon.2004.09.023

14. Oliver TM, Jugoslav K, Aleksandar P, Nikola D (2005) Synthetic activated carbons for the removal of hydrogen cyanide from air. Chem Eng Process Process Intensif. https://doi.org/10.1016/j.cep. 2005.03.003

15. Lillo-Ródenas MA, Cazorla-Amorós D, Linares-Solano A (2011) Benzene and toluene adsorption at low concentration on activated carbon fibres. Adsorption 17:473-481. https://doi.org/10.1007/ s10450-010-9301-7

16. Long C, Li Y, Yu W, Li A (2012) Removal of benzene and methyl ethyl ketone vapor: comparison of hypercrosslinked polymeric adsorbent with activated carbon. J Hazard Mater 203-204:251256. https://doi.org/10.1016/j.jhazmat.2011.12.010

17. Carratalá-Abril J, Lillo-Ródenas MA, Linares-Solano A, CazorlaAmorós D (2009) Activated carbons for the removal of low-concentration gaseous toluene at the semipilot scale. Ind Eng Chem Res 48:2066-2075. https://doi.org/10.1021/ie800521s

18. Oh JY, You YW, Park J et al (2019) Adsorption characteristics of benzene on resin-based activated carbon under humid conditions. J Ind Eng Chem 71:242-249. https://doi.org/10.1016/j.jiec.2018. 11.032
19. Brennan JK, Bandosz TJ, Thomson KT, Gubbins KE (2001) Water in porous carbons. Colloids Surf A Physicochem Eng Asp 187188:539-568. https://doi.org/10.1016/S0927-7757(01)00644-6

20. Carratalá-Abril J, Lillo-Ródenas MA, Linares-Solano A, CazorlaAmorós D (2010) Regeneration of activated carbons saturated with benzene or toluene using an oxygen-containing atmosphere. Chem Eng Sci 65:2190-2198. https://doi.org/10.1016/j.ces.2009. 12.017

21. Liu PKT, Feltch SM, Wagner NJ (1987) Thermal desorption behavior of aliphatic and aromatic hydrocarbons loaded on activated carbon. Ind Eng Chem Res 26:1540-1545. https://doi.org/ 10.1021/ie00068a008

22. Yuen FK, Hameed BH (2009) Recent developments in the preparation and regeneration of activated carbons by microwaves. Adv Colloid Interface Sci 149:19-27. https://doi.org/10.1016/j.cis. 2008.12.005

23. Yun JH, Choi DK, Moon H (2000) Benzene adsorption and hot purge regeneration in activated carbon beds. Chem Eng Sci 55:5857-5872. https://doi.org/10.1016/S0009-2509(00)00189-5

24. Melse RW, Ogink NWM (2005) Air scrubbing techniques for ammonia and odor reduction at livestock operations: review of on-farm research in the Netherlands. Trans Am Soc Agric Eng 48:2303-2313. https://doi.org/10.13031/2013.20094

25. Frilund C, Hiltunen I, Simell P (2021) Activated carbons for syngas desulfurization: evaluating approaches for enhancing lowtemperature $\mathrm{H} 2 \mathrm{~S}$ oxidation rate. ChemEngineering 5(2): https:// doi.org/10.3390/chemengineering5020023

26. Turk A, Sakalis E, Lessuck J et al (1989) Ammonia injection enhances capacity of activated carbon for hydrogen sulfide and methyl mercaptan. Environ Sci Technol 23:1242-1245. https:// doi.org/10.1021/es00068a008

27. Wang X, Ma Y, Ning P et al (2014) Adsorption of carbonyl sulfide on modified activated carbon under low-oxygen content conditions. Adsorption 20:623-630. https://doi.org/10.1007/ s10450-014-9607-y

28. Svoronost PDN, Bruno TJ (2002) Carbonyl sulfide: a review of its chemistry and properties. Ind Eng Chem Res 41:5321-5336. https://doi.org/10.1021/ie020365n

29. Sattler ML, Rosenberk RS, Sattler ML, Rosenberk RS (2006) Removal of carbonyl sulfide using activated carbon adsorption. J Air Waste Manag Assoc 56:219-224. https://doi.org/10.1080/ 10473289.2006.10464450

30. Qiu J, Ning P, Wang X et al (2016) Removing carbonyl sulfide with metal-modified activated carbon. Front Environ Sci Eng 10:11-18. https://doi.org/10.1007/s11783-014-0714-5

31. Nickolov RN, Mehandjiev DR (2004) Comparative study on removal efficiency of impregnated carbons for hydrogen cyanide vapors in air depending on their phase composition and porous textures. J Colloid Interface Sci 273:87-94. https://doi.org/10. 1016/j.jcis.2004.01.005

32. Dash RR, Balomajumder C, Kumar A (2009) Removal of cyanide from water and wastewater using granular activated carbon. Chem Eng J 146:408-413. https://doi.org/10.1016/j.cej.2008.06.021

33. Seredych M, van der Merwe M, Bandosz TJ (2009) Effects of surface chemistry on the reactive adsorption of hydrogen cyanide on activated carbons. Carbon N Y 47:2456-2465. https://doi.org/ 10.1016/j.carbon.2009.04.037

Publisher's Note Springer Nature remains neutral with regard to jurisdictional claims in published maps and institutional affiliations. 